\title{
Regional Contrasts in Consumers' Attitudes and Behavior Following the BP Oil Spill
}

Cornell Hospitality Quarterly

2016, Vol. 57(I) 66-8I

(C) The Author(s) 2015

Reprints and permissions:

sagepub.com/journalsPermissions.nav DOI: $10.1177 / 1938965515586619$

cqx.sagepub.com

@SAGE

\author{
Alex M. Susskind', Mark A. Bonn², Benjamin C. Lawrence', \\ and $\mathrm{H}$. Leslie Furr ${ }^{3}$
}

\begin{abstract}
In this paper, we examine how consumers' reactions to the British Petrolium (BP) oil spill and their attitudes about the Gulf of Mexico as a tourism destination differ as a function of the respondents' geographic location of residence and their past travel behavior. A survey conducted with 540 travelers and tourists, which began three weeks following the successful capping of the oil leak in the Gulf of Mexico, reveals that consumers' reactions to the oil spill varied by geographic location and past travel behavior. In particular, consumers from the southeast region, when compared with the three other geographic regions we sampled, had more negative views regarding the oil spill on a number of dependent measures. We also found that individuals who traveled to Florida in the two years prior to the oil spill reported higher perceptions of environmental risk than those individuals who had not traveled to Florida during that same time frame.
\end{abstract}

\section{Keywords}

marketing and sales; eco-tourism; tourism operations; communications and decision making; organizational behavior

Speculation currently surrounds the effect of the April 2010 BP oil spill in the Gulf of Mexico on the environment, economy, and image of the destination areas in the Gulf Coast states. Preliminary findings indicate a negative effect on the wildlife, fisheries, and coastal landscapes (McCrea-Strub et al. 2011). However, the full effect of the spill on the revenues of the hospitality and tourism industries and its influence on the longterm image of the Gulf Coast has yet to be empirically verified. One year after the spill, BP ran commercials on television, radio, and internet broadcasting that tourism was back on track, and BP had done everything in its power to make amends. However, even today, several years after the spill, not all consumers are convinced that the Gulf is a safe travel destination or that seafood caught in the Gulf of Mexico is safe to consume.

This project examines consumers' reactions to the oil spill and their attitudes about the Gulf region as a tourism destination based on their geographic proximity to Florida's Gulf of Mexico, and in particular, the northwest region of Florida that was directly influenced by the 2010 Gulf oil spill. Specifically, we examine the relationship of two factors: (1) geographic distance from the location of the areas affected by the oil spill and (2) consumers' past travel behavior to Florida in relation to several outcome measures. The outcome measures are as follows:

1. Perceptions of BP's corporate credibility

2. Perceptions of environmental risk following a manmade disaster
3. Reluctance to visit Florida in the next two years

4. Reluctance to visit Northwest Florida in the next two years

\section{Literature Review}

\section{Corporate Social Responsibility (CSR)}

Given the increased social awareness regarding the influence that business practices can have on the environment, a growing body of literature has emerged examining CSR and how firms deal with the ever-growing impact they have, across numerous industries, on the environment (Delmas, Etzion, and Nairn-Birch 2013). CSR constituents, both internal and external to an organization, determine the importance of CSR to a particular firm or industry and how CSR can positively or negatively affect its image and financial performance (Scholtens 2008). In other words, CSR is viewed as socially desirable actions that a firm engages in to create social well-being, voluntarily based on broader

\footnotetext{
'Cornell University, Ithaca, NY, USA

${ }^{2}$ Florida State University, Tallahassee, USA

${ }^{3}$ Georgia Southern University, Statesboro, USA

Corresponding Author:

Alex M. Susskind, School of Hotel Administration, Cornell University, 350 Statler Hall, Ithaca, NY 14853, USA.

Email:ams76@cornell.edu
} 
institutional influences from a company's macro and micro environment (Brammer, Jackson, and Matten 2012; Doh et al. 2010), "beyond the interests of the firm and that which is required by law" (McWilliams and Siegel 2001).

CSR is traditionally defined as two-dimensional (Carroll 1979, 1999): (1) ethical - actions not required by law but deemed important by social forces that can influence a business's success, and (2) philanthropic-where voluntary firm actions exceed the expectations of the societal forces. However, recent definitions of CSR describe it with five general dimensions that stakeholders normally consider to varying degrees (Inoue and Lee 2011): (1) employee relations - addresses issues such as employee health, safety, compensation, and benefits; (2) product quality (a proxy for consumer relations)-looks at the extent to which a firm delivers safe, innovative, quality products to their consumers; (3) community relations - considers the extent to which a firm supports the community with charity, education, and the like; (4) the environment - considers the extent to which firms engage in green practices such as conservation and production of environmentally friendly products and services; and (5) diversity - the extent to which a firm actively recruits, hires, and promotes protected minority groups. Each of the five dimensions introduced above was examined in several sectors of the hospitality industry (i.e., airline, casino, hotel, and restaurant). In their study, Inoue and Lee (2011) found that the five dimensions of CSR played differing roles in long-term and short-term profitability of each sector. Community relations-based CSR was positively related to both short-term and long-term profitability in the hotel and restaurant sectors. Hotels, restaurants, and local markets are clearly positively related to one another; however, these same tourism components were negatively related to the airline sector. The assumption here is that airline firms tend to form a tangential relationship to the communities they serve (Inoue and Lee 2011). As expected, Inoue and Lee (2011) established that product-based CSR was significantly related to profitability in the hotel, restaurant, and airline sectors indicating that consumers from these sectors react favorably to CSR initiatives in this sector (Inoue and Lee 2011). Finally, limited impacts by environmentally based CSR in all four sectors were revealed except for a positive long-term effect in the hotel sector (Inoue and Lee 2011). Research has also demonstrated that environmental issues and concerns do reach beyond the firm level to a macro or institutional level (Brammer, Jackson, and Matten 2012; Doh et al. 2010).

Existing work on CSR highlights the effects firms have on the five dimensions and how these accomplishments are related to firm performance, that is, how proactive firm behaviors influence firm performance. In this study, however, we are interested in behaviors that emerge reactively and are consequently considered by consumers. To do so, we introduced several CSR-related concepts that quantify consumers' opinions of CSR and the connection to man-made catastrophes such as the BP oil spill. We first examine product, community, and environmentally based CSR issues. Then, we introduce source credibility along with corporate credibility. Corporate credibility, in this case, describes the methods communication receivers and senders use to structure, send, and react to messages. We conclude with a discussion of risk perceptions, and how disruptive events may influence consumers' behavior.

\section{Source Credibility}

An extensive body of research in both the marketing and communication literature takes into account the influence of source credibility on consumer behavior (Pornpitakpan 2004). Source credibility is the degree to which a source is simultaneously observed as being both trustworthy and knowledgeable in the topics under consideration (Dholakia and Sternthal 1977). Credibility is characterized as a source that is honest and believable (trustworthy) when stating legitimate positions (expertise). Source credibility is a critical antecedent of persuasion. If the sender of a message is not viewed as credible, it is unlikely the message will be believable and have its intended effect (Miller 1987). In this study, we are interested in how source credibility is related to consumers' attitudes toward a company given their geographic location and proximity to a man-made disaster (the BP oil spill).

There is a rich history of persuasion research in the field of communication that considers both one-to-one and oneto-many communications designed to influence perceptions, attitudes, and behavior (Miller 1987). A common organizational application of persuasion is public relations. Public relations is viewed as the process of an organization (one) attempting to mold the discussion with and perceptions of the public (many) on issues of importance. The 1992 Tylenol scare is one of many examples of a successful public relations response to a crisis. In response to the crisis, Johnson \& Johnson recalled all Tylenol products to ensure the safety of consumers and demonstrated genuine concern through a set of carefully crafted, corporate messages. Conversely, several automobile companies (i.e., General Motors [GM] in 2014 and Toyota in 2010) have been criticized for both their handling of product defects and their subsequent handling of the recall and replacement of defective parts and products. How a company engages the public following a crisis is a matter of public relations, which is contingent on consumers' perceptions of source credibility (Harlow, Brantley, and Harlow 2011) or firm reputation (Lyon and Shimshack 2012).

\section{Corporate Credibility}

Corporate credibility (Goldsmith, Lafferty, and Newell 2000), a related construct to source credibility, is traditionally defined as the extent to which a company's internal and 
external communication is perceived as clear, direct, and believable. This concept, refined by Hon and Grunig (1999), focuses on the relationship between the organization, message, and consumers. Furthermore, corporate credibility (or reputation) includes factors such as good corporate citizenship or a company that is admired by others (Lyon and Shimshack 2012). Corporate credibility positively influences consumers' reactions to advertising messages and product performance (Goldberg and Hartwick 1990). Hence, corporate credibility is crucial to companies that run the risk of alienating consumers and losing business because of inconsistent actions with their corporate communication. Corporate credibility defines firms in two ways: First, companies need consumers to believe what the firm says; that is, they want their consumers to relate favorably to corporate messages when making purchasing decisions. Second, companies deliver their messages with the intent to accurately differentiate their firm from their competitors. Both elements are consistent with Hon and Grunig's (1999) conceptualization identifying the fact that corporate credibility emerges from the intersection of an organization and its agents' actions.

Corporate credibility connects well with CSR because companies who engage with their constituents directly influence consumers' appraisal of the company. Corporate credibility in this case captures how constituents view the product-based, community-based, and environment-based elements and the other CSR dimensions. Corporate credibility assesses how a company's actions are viewed by others in both the micro and macro (i.e., institutional) environment (Brammer, Jackson, and Matten 2012; Doh et al. 2010; Drori and Honig 2013; MacLean and Behnam 2010).

The BP oil spill offers a notable opportunity to test the idea of corporate credibility and CSR. The BP oil spill resulted in an extremely negative fiscal, social, and environmental consequence for the Gulf Coast (Reuters 2014). BP's obligation to restore a sense of order by repairing the multiple problems created by the oil spill was decided in court. BP is currently paying billions of dollars as a result of damage caused by the spill to businesses and residents affected directly and indirectly by the spill. In March 2014, BP lost their appeal to halt or modify the terms of the reparation agreement in the Fifth Circuit U.S. Appeals Court (Reuters 2014). While BP was in court trying to alter the terms of their settlement agreement, they were trumpeting their efforts to clean up and restore the Gulf region publicly via commercial advertisements on television and radio, and in print. One important premise is that CSR businesses are committed to a level of social responsibility that goes beyond traditional business interests. As previously noted, this interest is voluntary and should be proactive. In the case of the BP oil spill, the remediation cleanup and reparation conducted by the company was reactive, not proactive.
The connection between CSR and corporate credibility is clear. Organizations in a position to help proactively are likely to be regarded more favorably than companies, such as BP or GM, who are forced to make reparations after the fact. The existing social contract between businesses and stakeholders defines the corporation as a fair player in the system and has been examined in a variety of business settings (Lyon and Shimshack 2012; Scholtens 2008). This contract, rooted in institutional theory (Brammer, Jackson, and Matten 2012; Doh et al. 2010; Drori and Honig 2013; MacLean and Behnam 2010), is generally strong and defines the norms, obligations, and activities needed to maintain order in the economic-social exchange created by business enterprises (Brown and Dacin 1997; Drori and Honig 2013; MacLean and Behnam 2010; Murray and Vogel 1997; Sen and Bhattacharya 2001). In effect, for businesses to continue to operate as legitimate, credible entities (as described by institutional theory), they must balance the internal needs of the firm with the elements of the broader institutional environment, including but not limited to, government, local communities, suppliers, labor force, and consumers (Inoue and Lee 2011). A firm that fails to meet the broader expectations of legislation, social norms, and environmental concerns cannot expect to maintain a positive CSR image and/or corporate credibility.

Few studies have examined the overall regional impact of the BP oil spill. One study by Hoffman and Jennings (2011) outlined the probable fallout from the spill, identifying broad issues such as changing attitudes toward regulating the use and production of fossil fuels. Another examination of Gulf state residents' attitudes and perceptions encompassing the Gulf oil spill utilized phone surveys conducted from July 2010 through September 2010 (Safford, Ulrich, and Hamilton 2012). The phone surveys indicated that 70 percent of the respondents felt that BP was doing a fair or poor job responding to the spill (Safford, Ulrich, and Hamilton 2012). Eighty-six percent of those surveyed indicated that they understand a moderate amount or a great deal about the spill; however, only 25 percent of the respondents indicated that they trusted network television news as a source of information about the spill and an even lower number (17\%) trusted BP as an information source about the spill (Safford, Ulrich, and Hamilton 2012). In our next section, we discuss how consumers' regional affiliations influence attitudes and perceptions toward the BP oil spill and consumptive behavior as a traveler or tourist.

\section{Effects of Geography}

We expanded our analysis regarding the impact of the BP oil spill on consumers' attitudes and behavior beyond the work conducted by Safford, Ulrich, and Hamilton (2012), who limited their sample to select counties and parishes 
within the Gulf region. As noted above, our analyses measured specific elements of CSR using a broader national sample. To do so, we engaged in a spatial analysis.

A geographic and tourism spatial scale focuses on the links between tourist-generating and tourist-receiving areas. A spatial study utilizes a variety of metrics such as world distribution of climatic zones, regional assessment of tourist resources, and the local landscapes of resort destination areas. The geographical components of this spatial study represented the opinions of tourists at the trip source and the attributes that stimulated demand for tourism, including the geography, socioeconomic, and demographic characteristics (similar to a regional assessment approach). Spatial studies have shown that attitudes toward tourism vary greatly by geographic region and consumers' proximity to the tourism center/location under study (Harrill 2004). In a spatial study looking at attitudes toward tourism development in a specific region, Jurowski and Gursoy (2003) found that those residents who were heavy consumers of tourism and lived relatively close to the core of tourism reported more negative attitudes about tourism development, compared with those residents who were farther away from the development. Consistent with the studies that examine consumers based on geographic distance from a location/phenomenon of interest (Harrill 2004; Jurowski and Gursoy 2003; Raymond and Brown 2007), we believe that consumers' attitudes regarding tourism in the Gulf region following the BP oil spill will vary based on geographic or regional proximity.

To conduct a regional assessment approach consistent with spatial analysis, we employ the gravity model to segment consumers' travel to Gulf region destinations from their original home sites. The gravity model classification technique is often employed by researchers to form consumer groups based on geographic/spatial similarities (Bonn, Furr, and Uysal 1992; Furr, Bonn, and Seagle 1992; Niedercorn and Bechdolt 1969). The gravity model counts the distance between the tourist's origin site and the destination area, taking into account the population of origin site, attractiveness, and relative cost of the destination area. This distance variable can also be comprised of various combinations of physical distance, travel time, travel costs, and number of intervening opportunities used to measure the separation between an origin and a destination (Bonn, Furr, and Uysal 1992; Furr, Bonn, and Seagle 1992).

\section{Tourism in the Gulf Region}

A number of public-private organizations engaged in marketing activities designed to attract tourism travelers are firmly established in the affected Gulf coast area. These tourism organizations are known as destination marketing organizations (DMOs) and may be specifically represented by tourism development councils (TDCs), convention and visitors bureaus (CVBs), sports councils, and chambers of commerce. These organizations' primary funding source depends largely on the collection of "tourist" taxes that result from visitor spending in targeted destination areas. The majority of the revenue for these tourism agencies is collected in the form of tax receipts based on the direct purchase of traditional tourism products. These income producing products include accommodation taxes, shopping, dining, transportation, attractions, and recreation activities (e.g., boating, fishing, and golf). Organizations responsible for attracting visitors receive and spend a majority of this revenue. After the funding has been allocated, these organizations developed operating budgets that assign spending categories and design messages to attract visitors based on money-generating activities supported by these visitor-generated tax dollars. These activity-oriented messages then position their organizations in target market areas based on historical data. Identification of visitor origins or "feeder markets" comprise the most often used marketing and advertising strategies that appeal to specific visitor types through traditional advertising and promotion activities.

Privately owned and operated tourism-dependent businesses regularly support regional communications messages issued by the DMOs. Promotional techniques are utilized by resorts, hotels, attractions, tour operators, restaurants, and traditional recreational businesses. In addition, state tourism offices, governmental agencies, and associations representing the tourism industry invest in tourism promotion activities, further supporting such promotion activities.

All states bordering the Gulf of Mexico, including Florida, Alabama, Mississippi, Louisiana, and Texas, promote the seafood industry heavily. Commercial businesses harvest seafood and sell their perishable seafood products directly to distributors, retailers, and consumers (tourists). Thousands of restaurants promote and feature menu items prepared from fresh, locally harvested seafood products, which are high demand items sought particularly by visitors through millions of collective dining experiences along these Gulf state coastal zones. Seafood products harvested from this area also ship throughout the United States to retail customers such as seafood distributors, grocery chains, and restaurants. In this study, we wanted to examine how consumers viewed seafood harvested from the Gulf region following the oil spill and whether it raised concerns for them.

\section{Consumers' Views Regarding the Environment}

An emerging line of inquiry examines consumers' attitudes toward sustainability and the environment (Baker, Davis, and Weaver 2014; Raymond and Brown 2007; SirakayaTurk, Baloglu, and Mercado 2014; Susskind 2014). This research inquiry focuses on the actual and potential visitor 
reactions to the environment and sustainability practices (Budeanu 2007; Claver-Cortés et al. 2007; T. H. Lee 2009; J. S. Lee et al. 2010), the ethics behind business engagement in sustainability practices (Budeanu 2007; Tsai and Tsai 2008), and the notion that environmental sustainability relates to visitors' consumptive behaviors (Dodds, Graci, and Holmes 2010; Sigala 2014; Singh, Slotkin, and Vamosi 2007). Several research studies have documented the importance of sustainability indicators - environmental awareness and management, water quality monitoring, and visual pollution - to today's consumers (Baker, Davis, and Weaver 2014; Peiró-Signes et al. 2014; Roberts and Tribe 2008).

Another element of environmental sustainability relates to consumers' reactions to environmental issues, man-made and natural. These environmental issues include the influence of natural disasters such as hurricanes, tsunamis, flooding, and earthquakes (Robinson and Jarvie 2008) and the effect of man-made disasters such as oil spills, radiation, and greenhouse gases (Beamish 2001; McChristian 2010). Adjustment periods in the wake of disasters require delineation, cleanup, or remediation efforts and are designed to restore the affected communities to their pre-disaster conditions. This transition period to pre-disaster sensibilities requires the affected tourism destination areas to lower perceptions of consumer risk as a first step in the restoration of former levels of consumption behavior (Beamish 2001; Floyd et al. 2004; Quintal, Lee, and Soutar 2010; Van Winkle and MacKay 2008).

Consumers form attitudes and perceptions regarding catastrophic events by evaluating the recovery process and will assign responsibility (or blame) to parties involved who acted inappropriately. It matters little to consumers whether the inappropriate actions occurred during the catastrophic event or as part of the delineation and remediation process. As a result, consumers' views toward the environment, the businesses, and the agents involved in environmental protection and remediation vary with the perception of the brand/company's behavior.

\section{Consumer Risk Perceptions}

Following man-made disasters, the public reacts in a number of different ways ranging from disinterest to outrage. Public reactions can be focused on the individuals or companies responsible for causing the problem or the broader regulating agencies that are intended to prevent such disasters from occurring (Beamish 2001; Safford, Ulrich, and Hamilton 2012). Consumers influenced by both public reactions to the events and by institutional entities are involved in the determination of the level of risk they may face (Beamish 2001). In addition, research shows that today's consumers place high importance on environmental and health factors when making decisions related to food purchasing (Forbes et al. 2009). Finally, research has shown that as visitor perceptions concerning the environmental quality of a resource decline, consumers are less willing to visit and/or participate in activities associated with that element (Johns et al. 2001).

In a study of consumers' perceptions of destination risk, it was determined that of the various types of risk measured (human-induced, financial, service quality, socio-psychological, natural disasters, weather, and food safety), humaninduced risk was the most strongly associated with consumers' perceptions of overall risk to engage in tourism (Fuchs and Reichel 2006). While the other types of risk identified and measured by Fuchs and Reichel (2006) and Floyd et al. (2004) were also shown to be significant in the analyses, the findings from both studies suggest that a high level of human-induced risk is likely to be consistent with consumers' reduced interest in engaging in travel and tourism. In contrast, a positive destination image favorably influences satisfaction with tourism, purchase intentions, and repurchase intentions (T. H. Lee 2009). These findings and propositions are similar to a post-September 11, 2001, study that examined perceived risk and travel intentions among a group of residents from the New York Citydesignated marketing area (New York City, tri-state area, and Pennsylvania), displaying safety concerns as a significant deterrent to travel for the study participants (Floyd et al. 2004). In effect, consumers' desire to travel following man-made disasters is influenced by their perception of destination image and their perceptions of the risk to travel to those destinations.

\section{Research Questions}

In this study, consumer-based geographic groupings of the participants' state of origin and their travel behavior to Florida prior to the oil spill were used to create independent variables and establish consumers' perceptions of BP's corporate credibility. Consumers' perceptions of environmental risk, consumers' reluctance to visit Florida in the next two years, and consumers' reluctance to visit Northwest Florida in the next two years were used as dependent variables to test the following non-directional research questions:

Research Question: How is geographic distance from the oil spill and consumers' past travel behavior to Florida related to consumer perceptions of

- BP's corporate credibility?

- Environmental risk perceptions following a manmade disaster?

- Reluctance to visit Florida in the next two years?

- Reluctance to specifically visit Northwest Florida in the next two years? 


\section{Method}

\section{Participants}

A sample of 540 travelers/tourists was surveyed for this study. Study participants completed a survey that measured their attitudes and perceptions regarding the BP oil spill, its effect on the environment, and their past and future travel plans to Florida, especially Northwest Florida. Three weeks following the successful capping of the oil spill in the Gulf of Mexico, 107 participants $(N=107)$ completed the survey through an e-mail invitation they received from a travel magazine to which they subscribed. Following the first wave of data collection, another 433 participants $(N=433)$ received an invitation to take the survey online while dining at a full service, casual dining restaurant through November $2011 .{ }^{1}$ We selected restaurant patrons from 18 units of a single restaurant chain located in the Northeast and Midwest. These regions were chosen because they allowed the researchers to gather additional participants from two regions that were underrepresented in the travel magazine sample. Four of the restaurants sampled were in New Jersey, three were in New York, four were in Pennsylvania, two were in Ohio, two were in Michigan, and three were in Illinois.

\section{Sample Selection}

We selected this particular travel magazine because it boasted a national readership that tapped into travelers and tourists from across the country. In addition, one focus of the magazine's advertising strategy centered on travelers and tourists to Florida destinations. This magazine's national readership and its strong focus on Florida tourism match the research goals of this project. The survey was distributed to a random sample of 1,000 magazine subscribers. Respondents who completed the survey were entered into a drawing for a free week-long hotel stay at a resort. We had a 10.8 percent response rate; this response rate is lower than the reported response rate of Hayslett and Wildemuth (2004), who studied response rates for surveys administered in this fashion (web-based invitation to complete a web-based survey) and reported an average response rate of 33 percent. Reminders were communicated to non-respondents, complete with incentives to complete the survey, even though Anseel et al. (2010) found that reminders and incentives often do not yield consistently stronger response rates. For our restaurant guest sample, based on Visit Florida Research (2013), restaurants in large metropolitan areas in the Northeast and Midwest that were identified as the largest feeder markets to Florida were chosen to gain an additional sample of customers consuming hospitality services. With approval from corporate management, we approached each restaurant and subsequently asked guests to complete
Exhibit 1:

\section{Breakdown of Participants from Each Geographic Region.}

\begin{tabular}{lcc}
\hline & Frequency & $\%$ \\
\hline Gulf & 88 & 16.3 \\
SE & 113 & 20.9 \\
NE & 167 & 30.9 \\
Midwest/West & 172 & 31.9 \\
\hline
\end{tabular}

Note. SE $=$ Southeast; NE = Northeast.

a brief online survey regarding their perceptions of the BP oil spill and travel behavior. Guests who completed the survey were given a coupon for $\$ 5.00$ off a subsequent meal at any of the company's restaurants. Our goal was to collect 20 additional surveys from each restaurant; on average, 24 restaurant guests completed the survey from each restaurant, ranging from 20 to 26 . The useable response rate among the restaurant sample was quite high at 43 percent from the 1,000 invitations. This response rate is higher than the reported response rate of Hayslett and Wildemuth (2004), who found response rates for surveys administered in this fashion (paper invitation to complete a web-based survey) of 23 percent. Our higher than average response rate is consistent with the findings reported by Anseel et al. (2010), who found in their meta-analysis that response rates tend to be higher for consumer-based samples and are typically bolstered by personal delivery.

To ensure that the two samples were congruent and combinable, we compared all the dependent variables, plus age and gender using one-way analysis of variance (ANOVA) with sample as the factor. Because gender is strictly a categorical measure, we used a $\chi^{2}$ test instead. Results showed that the two samples were congruent as no significant differences emerged from the ANOVAs by sample. The $\chi^{2}$ test for gender proved to be significant, $\chi^{2}(1)=5.60, p=.02$. The magazine sample included 12 percent more women than the restaurant sample ( $75 \%$ vs. $63 \%$, respectively); however, both distributions fell within the range of 60 to 80 percent reported to be the distribution of women who are the primary decision makers for family or personal travel (Bond 2011; Ponchione 2012).

All 540 participants resided in the United States and represented thirty-one states. The survey participants were divided into four groups based on the geographic region they reported as their home (see Exhibit 1). Region 1 included 88 participants $(16.3 \%)$ from the Gulf states of Florida, Mississippi, Alabama, and Texas; Region 2 included 113 participants (20.9\%) from the southeastern states of Georgia, Kentucky, Tennessee, Virginia, West Virginia, North Carolina, and South Carolina; Region 3 included 167 participants (30.9\%) from the northeastern states of New York, New Jersey, Connecticut, Pennsylvania, 
Maryland, Massachusetts, and Maine; and Region 4 included 172 participants (31.9\%) from the midwestern and western states of Ohio, Indiana, Iowa, Illinois, Oklahoma, Michigan, Minnesota, Colorado, Idaho, Arizona, Montana, Utah, and California. Females made up 65 percent of the sample and the average age of the sample is 38.39 (standard deviation $[S D]=10.46$ ) ranging from 22 to 72 . As noted previously, women account for 60 to 80 percent of leisure travel spending decisions for family vacations and other personal travel, irrespective of the destination (Bond 2011; Ponchione 2012). Therefore, we believe that the sample consisting of 65 percent female participants offers a reasonable representation of travel decision makers. ${ }^{2}$

\section{Survey Items}

Study participants reported personal attitudes, perceptions, and travel behavior following the BP oil spill in the Gulf of Mexico. Participants were asked whether they had visited Florida in the two years prior to the oil spill (2009-2010) using a yes or no response format. Three hundred seventy participants $(68.5 \%)$ indicated they visited Florida during the two preceding years. ${ }^{3}$ They were also asked whether they planned to visit a tourist destination in Florida in the coming two years (2011-2012) using a yes, no, or undecided response format. Fifty-four participants (10\%) indicated they had a visit planned in the upcoming two years, $377(69.8 \%)$ indicated they did not plan a visit in the next two years, and 109 participants $(20.2 \%)$ indicated they were undecided at the time of survey administration.

Participants were asked seven individual questions on a five-point Likert-style scale to determine the extent to which the BP oil spill negatively affected their perceptions of future travel to Florida destinations, specifically Northwest Florida (Gulf Coast region), and environmental risk (measured as environmental quality, environmental safety, and safety to consume seafood from the Gulf of Mexico). Accordingly, 1 = no negative impact, 2 = low negative impact, 3 = neutral, $4=$ moderate negative impact, and $5=$ high negative impact. A high score on these items represents a high level of reported negative affect.

Participants' perceptions of BP's corporate credibility were recorded using a five-point Likert-style scale that measured agreement $(1=$ strongly disagree, 2 = somewhat disagree, 3 = neutral, $4=$ somewhat agree, and $5=$ strongly agree) with nine questions based on the items developed and presented by Hon and Grunig (1999). A high score on this scale indicated a high level of perceived corporate credibility. The steps we took to ensure content and construct validity of our survey items are presented in the following section.

\section{Content and Construct Validity}

Based on the work of Bergkvist and Rossiter (2007), we treated reluctance to visit Florida and reluctance to visit
Northwest Florida as single-item measures because intent to visit is classified as a singular object attached to a concrete attribute, much like attitude toward a brand or an ad. Research has clearly shown that with singular object items attached to a concrete attribute, no difference in the predictive ability of single-item and multiple-item measures has been found over time (Bergkvist and Rossiter 2007).

With the remaining survey items - a nine-item corporate credibility scale (Hon and Grunig 1999) and three items we created specifically for this study measuring consumers' perceptions of the environmental risk following a manmade disaster - we conducted a content validation to examine the measurement properties of the scale items following the procedure set forth by Hinkin and Tracey (1999).

\section{Procedure}

To conduct the content validation, we surveyed 139 business college undergraduates enrolled in marketing, human resource management, and organizational behavior courses. The students completed the content validation surveys for extra credit in their respective courses. The student raters were predominately male (56\%) and ranged from 19 to 26 years in age $(M=20.34)$.

Using Hinkin and Tracey's (1999) ANOVA technique for content validation, we started with two construct definitions: one to gauge "consumers' perceptions of environmental risk following a man-made disaster" and one to gauge "consumers' perceptions of corporate credibility." Perceptions of an environmental risk scale consisted of three items we developed specifically for this investigation; the nine-item corporate credibility scale was adapted from Hon and Grunig (1999). We used the following two specific definitions:

Definition 1: "Environmental risk perceptions" is defined as the importance individuals place on factors such as air and water quality, product safety, environmental safety, and general condition of natural resources. Definition 2: "Corporate credibility" is defined as the extent to which a company or corporation is seen as being fair, honest, and trustworthy, concerned about the public, and mindful of how company decisions can impact individuals both inside and outside the company.

Each student was given a survey that contained the twelve items to be rated. Sixty-nine students were given Definition 1 at the top of their survey and seventy students were given Definition 2 at the top of their survey. The student raters were asked to evaluate how well each of the twelve questions aligned with the definition given to them at the top of the page on a five-point scale where $1=n o$ agreement and $5=$ high agreement. The twelve questions across all 139 surveys were presented in four different sequences to control for any ordering effects of the questions. 


\section{Exhibit 2:}

Results of Principal Components Factor Analysis for the Corporate Credibility Scale and Environmental Risk Perceptions Scale.

(I)

(2)

Environmental risk perceptions items $(\alpha=.93)$

I. Perception of environmental quality

2. Perception of environmental safety

$-.03 \quad .90 \quad .27$

3. Safety to Gulf seafood

Corporate credibility items (adapted from Hon and Grunig 1999; $\alpha=.95$ )

I. I believe that BP would treat people like me fairly.

2. I believe that if BP makes an important decision, I know they will be concerned about people like me.

3. BP can be relied upon to keep its promises.

4. I believe that BP takes the opinions of people like me into account when making decisions.

5. I feel very confident about BP's skills.

6. BP has the ability to accomplish what it says it will do.

7. Sound principles seem to guide BP's behavior.

8. BP would not mislead people like me.

9. I am very willing to let BP make decisions for people like me.

$\begin{array}{lll}-.07 & .92 \quad .25\end{array}$

Reluctance to visit items

I. Reluctance to visit Florida

2. Reluctance to visit Northwest Florida

$\begin{array}{lll}-.07 & .93 & .12\end{array}$

$\begin{array}{lll}.86 & -.09 \quad .06\end{array}$

$\begin{array}{lll}.88 & -.06 & .05\end{array}$

$.89 \quad-.02 \quad .03$

$.90 \quad-.06 \quad .04$

$.91 \quad-.04 \quad .01$

$.77 \quad-.02-.06$

$\begin{array}{lll}.88 & .02 & -.06\end{array}$

$\begin{array}{lll}.78 & -.07 & -.06\end{array}$

$79 \quad .06 \quad .10$

$.06 \quad .40 \quad .86$

$\begin{array}{lll}.04 & .47 \quad .73\end{array}$

\section{Analyses}

Per Hinkin and Tracey's (1999) recommendations, the survey items were first factor analyzed. In this case, we used a covariance matrix as input with a Varimax rotation. The analyses revealed three distinct constructs explaining 79.32 percent of the variance, with no cross-loadings above .50 (factor loadings are presented in Exhibit 2). ${ }^{4}$

The second step is to conduct an assessment of how well the items aligned with the respective a priori construct definitions. This is done by conducting a one-way ANOVA and examining the means of each item against its a priori construct definition and the alternative definition, such that an item should match its a priori definition and be significantly different from the alternative definition. The means, standard deviations, and ANOVA output are presented in Exhibit 3. Based on the results of the initial factor analysis and the Hinkin and Tracey (1999) content validation procedure, two factors were confirmed: corporate credibility $(\alpha=$ .95 ) and perceptions of the environmental risk following a man-made disaster $(\alpha=.93)$. These two scales, along with the two single-item reluctance to visit measures, were used as dependent variables in our analyses below.

\section{Analyses}

To test the research questions presented, we examined the descriptive statistics and correlations among the variables. Multiple analysis of variance (MANOVA) compared the participants on two independent variables across two factors: (1) the geographic region in which they lived (Gulf,
Southeast [SE], Northeast [NE], Midwest/West) and (2) whether or not they visited Florida in the past two years (yes or $n o) .{ }^{5}$ The independent variables were tested among the participants using the six dependent measures previously described: (1) perceptions of BP corporate credibility, (2) consumers' perceptions of environmental risk, (3) reluctance to visit travel destinations in Florida, and (4) reluctance to visit travel destinations specifically in Northwest Florida (Gulf Coast region). The main effects were subsequently examined to provide further interpretations of the MANOVA results (correlations and descriptive statistics of the dependent measures are presented in Exhibit 4).

\section{Results and Discussion}

The results from the MANOVA (see Exhibit 5) revealed an interaction indicating that participants' prior visits to Florida and their geographic distance from the oil spill worked in concert with the dependent variables. The Pillai's Trace Statistic was significant $(.08, p<.001)$, based on the $F$ statistic, $F(12,1590)=3.57, p<.001, \eta^{2}=.04$. A closer look at the between-subjects effects revealed that the interaction effect noted previously likely emerged from a single variable - consumers' reluctance to visit Northwest Florida in the future, $F(3,531)=3.82, p=.01, \eta^{2}=.02$. Consumers from the southeast region, who did not visit Northwest Florida in the past two years, indicated that the BP oil spill negatively affected their intention to travel $(M=3.38$, standard error $[S E]=.25$ ) when compared with visitors from the southeast region who had visited Northwest Florida in the past two years, who indicated their intention to travel was 
Exhibit 3:

Content and Construct Validation.

\begin{tabular}{|c|c|c|c|}
\hline Scale Item & $\begin{array}{c}\text { Mean Rating Perceptions of } \\
\text { the Environment }\end{array}$ & $\begin{array}{l}\text { Mean Rating Corporate } \\
\text { Credibility }\end{array}$ & $F(d f)$ \\
\hline Perception of environment (quality) & 4.74 & 1.26 & $1595.23(1,138)$ \\
\hline Perception of environmental (safety) & 4.70 & 1.35 & $1325.68(1,138)$ \\
\hline Perception of environmental (seafood) & 4.63 & 1.30 & $1007.19(1,138)$ \\
\hline Corporate Credibility I & 1.81 & 4.15 & $374.02(I, 138)$ \\
\hline Corporate Credibility 2 & 1.82 & 3.92 & $217.16(1,138)$ \\
\hline Corporate Credibility 3 & 1.86 & 4.23 & $309.72(1,138)$ \\
\hline Corporate Credibility 4 & 1.77 & 3.37 & $0.74(1,138)$ \\
\hline Corporate Credibility 5 & 1.80 & 3.35 & $0.80(1,138)$ \\
\hline Corporate Credibility 6 & 1.76 & 3.99 & $338.39(1,138)$ \\
\hline Corporate Credibility 7 & 1.82 & 4.68 & $1176.49(1,138)$ \\
\hline Corporate Credibility 8 & 1.77 & 4.77 & $1493.05(1,138)$ \\
\hline Corporate Credibility 9 & 1.84 & 4.75 & II83.39 (I, 138) \\
\hline
\end{tabular}

Note. Items and means presented in boldface were rated significantly higher on the a priori dimension in comparison with the other items rated at the $p<.00$ I level.

Exhibit 4:

Correlations and Descriptive Statistics of the Dependent Measures.

\begin{tabular}{llllll}
\hline & $M(S D)$ & $(1)$ & $(2)$ & $(3)$ & $(4)$ \\
\hline (I) BP corporate credibility & $2.65(1.07)$ & 1.00 & & & \\
(2) Perceptions of the environment & $3.24(1.38)$ & $-.09 *$ & 1.00 & & \\
(3) Reluctance to visit Florida & $2.39(1.42)$ & .06 & $.59 * *$ & 1.00 & 1.00 \\
(4) Reluctance to visit Northwest Florida & $2.63(1.5 \mathrm{I})$ & .04 & $.70^{* *}$ & $.79 * *$ & 1.00 \\
\hline
\end{tabular}

Note. $N=539$ using listwise deletion.

*Correlation is significant at the .05 level (two-tailed). **Correlation is significant at the .0I level (two-tailed).

less disrupted by the oil spill $(M=2.84, S E=.17)$. None of the interaction effects for the other dependent variables were significant at the $p<.05$ level. The correlation matrix revealed a strong association between perceived environmental risk and reluctance to travel to Florida $(r=.59, p<$ .01 ) and reluctance to travel to Florida's Gulf Coast region $(r=.59, p<.01)$. We present the findings from the analysis of the main effects in the following section.

\section{Main Effects for Geographic Region}

In this set of analyses, the differences between the dependent variables were based on the geographic region in which the respondents lived. Four of the dependent variables were statistically significant in the analyses.

Corporate credibility. Consumers' perceptions of BP's corporate credibility were significantly different across the four geographic regions, $F(3,531)=3.72, p=.01, \eta^{2}=.02$. Duncan's multiple range test revealed consumers in the SE region viewed BP's credibility $(M=2.32)$ statistically lower than the other three regions at the $p<.05$ level $(M=2.64$,
$M=2.74, M=2.91$, for the Midwest/West, NE, and Gulf regions, respectively). This finding shows that participants from the Gulf's large SE feeder market viewed BP's actions more negatively.

Environmental risk perceptions. Consumers' perceptions of environmental risk in the Gulf due to the oil spill were significantly different based on geographic region, $F(3,531)=$ $3.10, p=.03, \eta^{2}=.02$. Duncan's multiple range test revealed consumers in the SE region viewed the effect of the oil spill on environment in the Gulf more negatively $(M=3.67)$ than the other three regions $(M=3.16, M=3.10, M=3.18$, for the Gulf, Midwest/West, and NE regions, respectively). The SE participants are heavy travelers to Florida, as residents of Georgia and North Carolina alone make up nearly 15 percent of domestic travelers to Florida (Visit Florida 2013). News of contamination and shutdowns in Gulf destinations obviously hit this group the hardest.

Reluctance to visit Florida in the next two years. Consumers' reported reluctance to visit Florida as a tourism destination was significantly different based on the geographic region 


\section{Exhibit 5:}

Summary Results of MANOVA Between-Subjects Effects.

\begin{tabular}{lccc}
\hline Visit in Past Two Years & $F(I, 53 I)$ & $p$ & $\eta^{2}$ \\
\hline Corporate credibility & 0.04 & .84 & .00 \\
Risk perceptions & 0.49 & .001 & .02 \\
Reluctance to visit Florida & 7.21 & .007 & .01 \\
Reluctance to visit Northwest Florida & 0.002 & .96 & .00 \\
\hline Geographic Region & $F(3,531)$ & $p$ & $\eta^{2}$ \\
\hline Corporate credibility & 3.72 & .01 & .02 \\
Risk perceptions & 3.10 & .03 & .02 \\
Reluctance to visit Florida & 4.90 & .002 & .03 \\
Reluctance to visit Northwest Florida & 5.80 & .001 & .03 \\
\hline Visit in past two years $\times$ Geographic region & $7(3,531)$ & $p$ & $\eta^{2}$ \\
\hline Corporate credibility & 1.82 & .14 & .01 \\
Environmental risk perceptions & 0.91 & .44 & .01 \\
Reluctance to visit Florida & 1.58 & .19 & .01 \\
Reluctance to visit Northwest Florida & 3.82 & .01 & .02 \\
\hline
\end{tabular}

Note. $N=539$ using listwise deletion.

in which they lived, $F(3,531)=4.09, p=.002, \eta^{2}=.03$. Duncan's multiple range test revealed consumers in the SE region indicated that the impact of the oil spill more negatively affected their desire to travel to Florida for tourism $(M=2.79)$ compared with the other three regions $(M=2.40$, $M=2.26, M=2.26$, for the Gulf, Midwest/West, and NE regions, respectively).

Reluctance to visit Northwest Florida in the next two years. Consumers' reported reluctance to visit Northwest Florida as a tourism destination was significantly different based on the geographic region in which they lived, $F(3,531)=5.80, p=$ $.001, \eta^{2}=.03$. Duncan's multiple range test revealed consumers in the SE region indicated that the impact of the oil spill more negatively affected their desire to travel to Northwest Florida for tourism $(M=3.01)$ compared with the Gulf $(M=2.67)$, Midwest/West $(M=2.59)$ and NE regions $(M=$ 2.38). The Gulf region was not significantly different from the SE group or Midwest/West and NE groups.

The SE group is a large feeder market for Northwest Florida and Florida as a whole. Following the oil spill, it is clear that this geographic group looked elsewhere for travel and tourism opportunities. The implications of this finding are reviewed in the following section.

\section{Main Effects for a Recent Past Visit to Florida}

The second set of main effects studied differences in dependent variables based on the participants' visitation to Florida during the two years prior to the BP oil spill. Two of the four dependent variables were statistically significant in the model.

Corporate credibility. Consumers' perceptions of BP's corporate credibility were not significantly different across the two groups of recent pre-oil spill visitors compared with those who did not visit, $F(1,531)=.04, p=.84, \eta^{2}=.00$; $M=2.67, M=2.65$, for visit and no visit, respectively. The data show that BP has a low level of credibility consistently among this set of respondents.

Perceptions of the environment. Consumers' perceptions of environmental risk in the Gulf due to the oil spill were significantly different across the two groups of recent pre-oil spill visitors and those who did not visit, $F(1,537)=10.49$, $p=.001, \eta^{2}=.02 ; M=3.41, M=2.99$, for visit and no visit, respectively. The data show that those participants who had previously visited reported a higher level of concern over the environment as a result of the oil spill. This suggests that the participants had an idea of what to expect while visiting and that the reported disruption from the oil spill was more meaningful to them, with a heightened awareness of the travel-related activities that may have been impacted by the spill and how future travel-related activities might be unsafe, such as water sports, sun bathing and swimming, and Gulf seafood consumption.

Reluctance to visit Florida in the next two years. Consumers' reported reluctance to visit Florida as a tourism destination following the oil spill significantly differed across the two 
groups of recent pre-oil spill visitors and those who did not visit, $F(1,537)=7.21, p=.007, \eta^{2}=.01 ; M=2.31, M=$ 2.67 , for visit and no visit, respectively. Those who had not recently visited Florida showed a slightly higher concern than those who had visited prior to the oil spill, but neither group reported a high level of concern. This would be expected given the large number of tourism destinations in Florida that do not directly involve travel to the Gulf region.

Reluctance to visit Northwest Florida in the next two years. Consumers' reported reluctance to visit Northwest Florida as a tourism destination following the oil spill was not significantly different across the two groups of recent pre-oil spill visitors and those who did not visit, $F(1,537)=.002, p=$ $.96, \eta^{2}=.00 ; M=2.66, M=2.65$, for yes and no, respectively. Prior travelers to Florida and those who have not recently visited Florida both showed minimal concerns regarding a trip to Northwest Florida in the coming years.

\section{Conclusion}

The multivariate research question we proposed in this study examined the relationship of consumers' geographic location and travel history with their reactions to BP and attitudes toward tourism in the Gulf region. The tests revealed that consumers from the SE region who had not traveled to the affected region in the previous year reported that the BP oil spill more negatively affected their intention to travel to the area in the future. This, in conjunction with the results from the tests of the main effects, highlights that the SE region, compared with the other three regions, was more negatively affected by the oil spill. From a marketing perspective, this shows that under these circumstances, potential new tourists or lapsed users may be harder to secure as future consumers. Those responsible for marketing to tourists and meeting planners need to be aware of these negative perceptions and focus their marketing efforts on product and services that can build on demand to visit the Gulf region, while minimizing perceived risks and defections to other regions not directly affected by the spill. Our findings show that there are regional differences in how consumers react to disasters and that in this case, specialized marketing attention to the SE region with a particular focus on the safety of recreational activities and seafood consumption may be beneficial.

Although all geographic regions reported very low scores for corporate credibility, the southeast region's statistically significant lowest score presents opportunities for further research. Atlanta, Georgia, is the top feeder market to Northwest Florida (Craul 2012). Atlanta also is equidistant in terms of drive time from Florida's northwest resort destinations as it is to Florida's northeast coastal resort destinations situated along the Atlantic Ocean. This is particularly relevant given BP's mixed messaging since the spill.
On one hand, BP reports in the press and through advertisements that they are committed to cleaning up the region and restoring business back to pre-spill levels. On the other hand, they are in court fighting to change the terms of the settlement agreement (Reuters 2014). These mixed messages present an interesting decision-making opportunity for this subregion's consumers given Atlanta's geographic location. Information about world news is also distributed by the Cable News Network (CNN), which is based in Atlanta. Anecdotally, CNN was a primary, ever-present channel for distributing highly repetitive information about the BP disaster to the southeastern region. Individuals residing in the coastal zone of the Gulf received continuous, frequently updated local news that presented many different storylines pertaining to specific local issues happening in their communities. CNN's news updates were not nearly as informative or as frequent regarding the oil spill. The network aired the same news loop for several days before their sources were able to provide updated featured stories pertaining to the BP oil spill disaster.

In terms of tourism, this disaster occurred during the height of what has historically been the busiest time for the summer vacation decision-making process. Confirmation or cancellation activity concerning upcoming summer reservations are normally finalized during the months of April and May along Florida's northwest Gulf Coast. Each year from Memorial Day weekend (last weekend in May) through Labor Day weekend (first weekend in September), millions of visitor-days are logged specifically by vacationers residing in the Atlanta Area of Dominant Influence (ADI) . In the event of future environmental issues, tourism boards in the Gulf region should understand the implications of regional consumer differences and tailor their promotional materials accordingly. Specifically, based on the findings of our study, marketers should develop and execute two strategies to promote Gulf tourism: one for localized markets that have more direct information and exposure to the issues and one for broader national markets where the information and exposure is diluted somewhat.

Florida is a large state that attracts more than 93 million visitors annually, representing a 90 percent repeat visitor rate from this annual total (Visit Florida 2011, 2013). The Gulf region makes up a significant portion of the drive market for tourists residing in the southeastern area of the United States. Our findings suggest that there are some lingering regional effects from the SE region. Despite the many destinations in Florida that do not involve Gulf tourism (i.e., Disney, Daytona, Miami), prospective vacationers to Florida's northwest Gulf Coast region residing in the southeastern United States were immediately and continuously bombarded with media messages from competitive destinations attempting to take advantage of the situation caused by the BP oil disaster (Craul 2012). Coastal and noncoastal destinations flooded key feeder markets to Northwest 
Florida's Gulf Coast with solicitations to take their summer 2010 and 2011 vacations at areas along the South Carolina coast. Myrtle Beach, Charleston, and Hilton Head Island, S.C., resort destinations boasted safe, clean beaches. Many Florida resorts along the Atlantic Ocean also saturated feeder markets for Northwest Florida with invitations and solicitations to book vacations elsewhere, capitalizing on their equidistant location especially from Atlanta, Georgia (Craul 2012). Because consumers' reported concerns regarding their reluctance to visit Northwest Florida as a tourism destination across the whole sample ranged from $M=2.38$ to $M=3.01$ on a five-point scale for the four geographic regions, the Gulf Coast still has an uphill battle to bring business back into the region, despite reports that tourism has returned to pre-spill levels (Craul 2012; Harlow, Brantley, and Harlow 2011; Safford, Ulrich, and Hamilton 2012).

As previously noted, our data show us that there are two distinct markets that feed tourism in the region: a localized market and a more broad, national market. For CVBs, tourism boards, meeting planners, and others with a stake in Gulf tourism, a sound strategy for building business should focus on developing advertising that addresses these two markets. A targeted focus across both markets should promote activities and attractions that have truly been restored and rejuvenated, and focus less on BP and their actions, because BP's corporate credibility is low and still remains in question (Reuters 2014).

Within a year of the BP oil spill, we were able to capture consumers' reactions to and perceptions of the spill, and how it shaped their plans for future travel to Florida. Our study showed that consumers had concerns over the effect of the oil spill, and these concerns varied by geographic area and prior exposure. Occupancy levels for the lodging industry reported for May through September 2010 were at historic lows in Northwest Florida, and cancellation rates were at historic highs (Smith Travel Research 2012). Given these findings, it would be wise to examine consumers' perceptions again, now that more than several years have passed.

\section{Limitations}

There are several limitations of this study that we feel are important to address. First, this study only focused on consumers' past travel and future intention to travel to Northwest Florida and Florida in general. Our findings documented that more than two-thirds of respondents indicated they had visited Florida within the past two years, showing that our study participants were a representative sample of recent, pre-oil spill visitors to Florida. We fully recognize that other Gulf Coast states were affected and note that not collecting data regarding other Gulf states is a limitation. Future research should examine a broader base of affected areas to determine if the effects of the oil spill were consistent across the entire region. Second, this study was crosssectional in design. Therefore, we are unable to draw any causal inferences from the data. Longitudinal data can provide a more accurate picture of consumers' reactions to the oil spill and how their behavior, perceptions, and attitudes have evolved since 2011. Last, we only collected information regarding consumers' perceptions of risk related to health, safety, and the environment. There are other risk factors - time, cost, and aesthetics - that may also be important factors that influence consumers' decisions to travel. Given these findings, additional research should be conducted to further define risk perceptions and the influence they have in decision-making processes.

\section{Implications}

Clearly, BP continues to promote travel to the Gulf states and has made a concerted effort to improve their corporate credibility through advertising. Future research could address the success of such actions (much like the study conducted by Harlow, Brantley, and Harlow 2011) and determine whether consumers remain concerned about travel and tourism in Florida and particularly in Florida's northwest Gulf region. Because occasional follow-up reports appear about this disaster, many of which are timed to the anniversary dates of the beginning and capping of the BP oil leak disaster, media tend to feature findings based on scientific studies, in part, supported by BP settlement dollars, pertaining to the safety of the environment. Seafood, in particular, remains a topic being closely and continuously monitored. As of April 2014, reports show that damage to wildlife is lingering for both sea life that is caught for human consumption (e.g., yellowfin tuna, bluefin tuna, blue crabs, redfish, and oysters) and sea life that is not part of the seafood supply (e.g., bottlenose dolphins, sea turtles, and sperm whales; Krupnick 2014). These findings are particularly troubling for tourism as Gulf seafood for consumption and Gulf area sea wildlife are key drivers of tourism. Thus, a future study should further address perceptions consumers hold pertaining to Gulf seafood product safety and their purchase habits concerning these products. Although we demonstrated that consumers had concerns regarding the safety to consume Gulf seafood directly after the oil spill, a closer look at changes to supply and demand patterns from 2010 going forward would be informative.

Through this study, we were able to identify and test several of the risk classifications identified by Fuchs and Reichel (2006) and Floyd et al. (2004) under new and different circumstances. From Floyd et al. (2004), we identified consumers' concerns over safety based on concerns over seafood consumption and environmental health and safety, and from Fuchs and Reichel (2006), we identified consumers' concerns over food safety. It is important to 
note that the terrorism-based context of 9/11 and travel to Israel are very different scenarios from the scenario we studied; our study found significant effects for several risk perceptions that were introduced through those studies, which we were able to apply to the BP oil spill. As such, we have adapted established risk elements from existing studies that addressed completely different disasters or risk scenarios and successfully tested them in a new context. Furthermore, we determined that in concert with their risk perceptions, consumers' geographic/regional proximity to the disaster was also a significant factor. In our study, we found that there were regional differences in how people reacted to the spill. Contrary to the findings of Jurowski and Gursoy (2003), those who were the closest to the oil spill did not report the most negative attitudes. We found that the most negative reactions came from consumers in Florida's largest feeder market for tourism (i.e., the heavy users), not by the local Gulf residents. Our findings provide support for measuring risk perceptions in concert with geographic distance. The approach we have taken also opens the door to many additional scenarios where these findings and this methodology could apply_floods, fires, and chemical/biological/radiation contamination and treatment plant failures.

\section{Declaration of Conflicting Interests}

The authors declared no potential conflicts of interest with respect to the research, authorship, or publication of this article.

\section{Funding}

The authors received no financial support for the research, authorship, or publication of this article.

\section{Notes}

1. We collected data from a national sample following the cap of the leak (in early December, 2010). That data collection process took approximately one year and was completed by November 2011. The first draft of this paper was submitted in October of 2012, eleven months after the data collection process was concluded. While some studies are published quite quickly, other studies take longer to execute. We believe this study is timed similarly to Floyd et al. (2004), which addressed consumers' risk perceptions following 9/11. Likewise, a more recent study by Kosova and Enz (2012) revisited the 9/11 attacks in concert with the financial crisis to compare and contrast the effects of the shocks on the lodging market.

To address a concern from an anonymous reviewer over the timeliness of the presentation of this research, we reviewed both of the O'Neill \& Lloyd-Jones articles and the other articles in the special issue of the Cornell Hotel and Restaurant Quarterly in October 2002 that addressed 9/11. These studies (Enz \& Canina 2002; O’Neill \& Lloyd-Jones 2001) certainly highlighted how the market was affected by $9 / 11$. They were not, however, consumer-based studies such as ours. We have found two academic studies that address this issue in a way similar to ours. One study (cf. Harlow, Brantley, and Harlow 2011) examines BP's communication from their website on July 26, 2011, to assess elements of image repair. The second study (cf. Safford, Ulrich, and Hamilton 2012) conducted phone surveys of Gulf state residents from July through September 2010, to assess residents' reactions to the spill. Our study takes a more macro look by using a national sample, addressing comparable issues and appears to be the first academic, consumer-based study of its kind conducted. News outlets and magazines have covered this issue regularly since April 2010. However, there is still conflicting information regarding BP's corporate behavior, the impact of the spill and the cleanup, and how consumers continue to react to it (cf. Reuters 2014).

2. To determine whether the demographic variables we measured had a relationship with the dependent variables under study here, we used a one-way analysis of variance (ANOVA) with sex as the factor to examine how sex was related to corporate credibility, revisit intentions, and perceptions of environmental risk. At the $p<.05$ level, there were no significant differences in the responses for the female and male participants. Furthermore, we correlated age (which was measured continuously) with the same dependent variables; none of the relationships were significant at the $p<.05$ level.

3. According to Visit Florida Research (2013), 56.3 percent of travelers who visited Florida came from ten states (in decreasing volume from): Georgia (10.6\%), New York (8.9\%), Texas (5.7\%), Illinois (5.6\%), New Jersey (4.5\%), Michigan (4.4\%), Ohio (4.4\%), Alabama (4.2\%), North Carolina (4.1\%), and Pennsylvania (3.9\%). Our sample captured respondents from all of those key markets identified above, plus twenty-one others. In addition, a multiyear study of the southwest Florida region that included data from the years 2005 to 2012 from 44,400 consumers indicated that 34.9 percent of the respondents had not visited Florida before (Furr, Bonn, and Peden 2013). We, therefore, believe we have accurately captured a reasonable sample of the traveling public.

4. We included the two single-item reluctance to visit measures in the factor analyses to further demonstrate the discriminant validity of the scale items. We would expect the two reluctance to visit items to be closely related, but because they each measured a single, discernable attribute (reluctance to visit Florida and/or Northwest Florida), they should be treated as single items (cf. Bergkvist and Rossiter 2007).

5. We used the Gravity Model to determine the spatial groupings for the various regions based on the research of Bonn, Furr, and Uysal (1992) and Furr, Bonn, and Seagle (1992). Specifically, in this application, we only considered the geographic distance to Florida attractions from the point of origin of the study participants. The Gulf region was defined by a partial day's distance, The southeast region was defined as a half day's distance, and the northeast and midwest/west regions were defined as full day's distance or more (likely involving air travel).

\section{References}

Anseel, F., F. Lievens, E. Schollaert, and B. Choragwicka. 2010. Response rates in organizational science, 1995-2008: A 
meta-analytic review and guidelines for survey researchers. Journal of Business Psychology 25:335-49.

Baker, M. A., E. A. Davis, and P. A. Weaver. 2014. Eco-friendly attitudes, barriers to participation, and differences in behavior at green hotels. Cornell Hospitality Quarterly 55 (1): 89-99.

Beamish, T. D. 2001. Environmental hazard and institutional betrayal: Lay-public perceptions of risk in the San Luis Obispo County oil spill. Organization \& Environment 14 (1): 5-33.

Bergkvist, L., and J. R. Rossiter. 2007. The predictive validity of multiple-item versus single-item measures of the same constructs. Journal of Marketing Research 44 (2): 175-84.

Bond, M. 2011. Woman travel statistics-80\% of all travel decisions made by women. http:/gutsytraveler.com/womentravel-statistics/ (accessed April 28, 2015).

Bonn, M. A., H. L. Furr, and M. Uysal. 1992. Seasonal variation of coastal resort visitors: Hilton Head Island. Journal of Travel Research 31 (1): 50-56.

Brammer, S., G. Jackson, and D. Matten. 2012. Corporate social responsibility and institutional theory: New perspectives on private governance. Socio-Economic Review 10 (1): 3-28.

Brown, T. J., and P. A. Dacin. 1997. The company and the product: Corporate associations and consumer product responses. The Journal of Marketing 61 (1): 68-84.

Budeanu, A. 2007. Sustainable tourist behaviour-A discussion of opportunities for change. International Journal of Consumer Studies 31 (5): 499-508.

Carroll, A. B. 1979. A three-dimensional model of corporate social performance. Academy of Management Review 4:497-505.

Carroll, A. B. 1999. Corporate social responsibility: Evolution of a definitional construct. Business \& Society 38 (3): 268-95.

Claver-Cortés, E., J. F. Molina-Azorín, J. Pereira-Moliner, and M. D. López-Gamero. 2007. Environmental strategies and their impact on hotel performance. Journal of Sustainable Tourism 15 (6): 663-79.

Craul, B. 2012. Personal interview with chairman. Florida Restaurant and Lodging Association.

Delmas, M. A., D. Etzion, and N. Nairn-Birch. 2013. Triangulating environmental performance: What do corporate social responsibility ratings really capture? The Academy of Management Perspectives 27 (3): 255-67.

Dholakia, R. R., and B. Sternthal. 1977. Highly credible sources: Persuasive facilitators or persuasive liabilities? Journal of Consumer Research 3 (4): 223-32.

Dodds, R., S. R. Graci, and M. Holmes. 2010. Does the tourist care? A comparison of tourists in Koh Phi Phi, Thailand and Gili Trawangan, Indonesia. Journal of Sustainable Tourism 18 (2): 207-22.

Doh, J. P., S. D. Howton, S. W. Howton, and D. S. Siegel. 2010. Does the market respond to an endorsement of social responsibility? The role of institutions, information, and legitimacy. Journal of Management 36:1461-85.

Drori, I., and B. Honig. 2013. A process model of internal and external legitimacy. Organization Studies 34 (3): 345-76.

Enz, C. A., and L. Canina. 2002. The best of times, the worst of times: Differences in hotel performance following 9/11. Cornell Hotel and Restaurant Administration Quarterly 43(5): 41-52.
Floyd, M. F., H. Gibson, L. Pennington-Gray, and B. Thapa. 2004. The effect of risk perceptions on intentions to travel in the aftermath of September 11, 2001. Journal of Travel \& Tourism Marketing 15 (2-3): 19-38.

Forbes, S. L., D. A. Cohen, R. Cullen, S. D. Wratten, and J. Fountain. 2009. Consumer attitudes regarding environmentally sustainable wine: An exploratory study of the New Zealand marketplace. Journal of Cleaner Production 17 (13): 1195-9.

Fuchs, G., and A. Reichel. 2006. Tourist destination risk perception: The case of Israel. Journal of Hospitality \& Leisure Marketing 14 (2): 83-108.

Furr, L. H., M. A. Bonn, and E. Seagle. 1992. Disaggregating seasonal demand of a coastal resort. Visions in Leisure and Business 10 (3): 36-52.

Furr, L. H., M. A. Bonn, and J. Peden. 2013. The impact of the recent recession upon Tourism behavior. Academic and Business Research Institute International Conference, March: New Orleans.

Goldberg, M. E., and J. Hartwick. 1990. The effects of advertiser reputation and extremity of advertising claim on advertising effectiveness. Journal of Consumer Research 17 (2): 172-9.

Goldsmith, R. E., B. A. Lafferty, and S. J. Newell. 2000. The impact of corporate credibility and celebrity credibility on consumer reaction to advertisements and brands. Journal of Advertising 29 (3): 43-54.

Harlow, W. F., B. C. Brantley, and R. M. Harlow. 2011. BP initial image repair strategies after the Deepwater Horizon spill. Public Relations Review 37 (1): 80-3.

Harrill, R. 2004. Residents' attitudes towards tourism development: A literature review. Journal of Planning Literature 18 (3): 251-66.

Hayslett, M. M., and B. M. Wildemuth. 2004. Pixels or pencils? The relative effectiveness of web-based versus paper surveys. Library \& Information Science Research 26:73-93.

Hinkin, T. R., and J. B. Tracey. 1999. An analysis of variance approach to content validation. Organizational Research Methods 2:175-86.

Hoffman, A. J., and P. D. Jennings. 2011. The BP oil spill as a cultural anomaly? Institutional context, conflict, and change. Journal of Management Inquiry 20 (2): 100-12.

Hon, L. C., and J. E. Grunig. 1999. Guidelines for measuring relationships in public relations. Institute for Public Relations. www.instituteforpr.com (accessed April 28, 2015).

Inoue, Y., and S. Lee. 2011. Effects of different dimensions of corporate social responsibility on corporate financial performance in tourism-related industries. Tourism Management 32 (4): 790-804.

Johns, G. M., V. R. Leeworthy, F. W. Bell, and M. A. Bonn. 2001. Socioeconomic study of reefs in Southeast Florida (Research Report for Broward County Department of Planning and Environmental Protection). Fort Lauderdale, FL: Hazen and Sawyer.

Jurowski, C., and D. Gursoy. 2003. Distance effects on residents' attitudes toward tourism. Annals of Tourism Research 31 (2): 296-312.

Kosová, R., and C.A. Enz. 2012. The terrorist attacks of 9/11 and the financial crisis of 2008: The impact of external shocks on 
US hotel performance. Cornell Hospitality Quarterly 53(4): 308-325.

Krupnick, E. 2014. 10 animals who are still hurting from the BP oil spill. Huffington Post, April 20. http://www.huffingtonpost.com/2014/04/20/animals-bp-oil-spill_n 5173016 . html?utm_hp_ref=tw (accessed April 21, 2014).

Lee, J. S., Li-Tzang (Jane) Hsu, H. Han, and Y. Kim. 2010. Understanding how consumers view green hotels: How a hotel's green image can influence behavioural intentions. Journal of Sustainable Tourism 18 (7): 901-14.

Lee, T. H. 2009. A structural model to examine how destination image, attitude, and motivation affect the future behavior of tourists. Leisure Sciences 31 (3): 215-36.

Lyon, T. P., and J. P. Shimshack. 2012. Environmental disclosure: Evidence from Newsweek's green companies rankings. Business \& Society, published online before print 0007650312439701.

MacLean, T. L., and M. Behnam. 2010. The dangers of decoupling: The relationship between compliance programs, legitimacy perceptions, and institutionalized misconduct. Academy of Management Journal 53 (6): 1499-520.

McChristian, L. 2010. Oil spill provides a teachable moment for our industry. Florida Underwriter 26 (7): 16-18.

McCrea-Strub, A., K. Kleisner, U. R. Sumaila, W. Swartz, R. Watson, D. Zeller, and D. Pauly. 2011. Potential impact of the Deepwater Horizon oil spill on commercial fisheries in the Gulf of Mexico. Fisheries 36 (7): 332-36.

McWilliams, A., and D. Siegel. 2001. Corporate social responsibility: A theory of the firm perspective. Academy of Management Review 26 (1): 117-27.

Miller, G. R. 1987. Persuasion. In Handbook of communication science, ed. C. R. Berger and S. H. Chaffee, 446-83. Newbury Park: Sage.

Murray, K. B., and C. M. Vogel. 1997. Using a hierarchy-ofeffects approach to gauge the effectiveness of corporate social responsibility to generate goodwill toward the firm: Financial versus nonfinancial impacts. Journal of Business Research 38 (2): 141-59.

Niedercorn, J. H., and B. V. Bechdolt. 1969. An economic derivation of the "gravity law" of spatial interaction. Journal of Regional Science 9 (2): 273-82.

O‘Neill, J. W., and A. R. Lloyd-Jones. 2001. Hotel values: In the aftermath of September 11, 2001. The Cornell Hotel and Restaurant Administration Quarterly 42(6): 10-21.

Peiró-Signes, A., Maria-Del-Val Segarra-Ona, R. Verma, J. Mondejar-Jimenez, and M. Vargas-Vargas. (2014). The impact of environmental certification on hotel guest ratings. Cornell Hospitality Quarterly 55 (1): 40-51.

Ponchione, A. 2012. Woman travelers influence trends. http:// www.hotelnewsnow.com/Articles.aspx/8352/Womentravelers-influence-trends (accessed April 28, 2015).

Pornpitakpan, C. 2004. The persuasiveness of source credibility: A critical review of five decades' evidence. Journal of Applied Social Psychology 34 (2): 243-81.

Quintal, V. A., J. A. Lee, and G. N. Soutar. 2010. Risk, uncertainty and the theory of planned behavior: A tourism example. Tourism Management 31 (6): 797-805.
Raymond, C., and G. Brown. 2007. A spatial method for assessing resident and visitor attitudes towards tourism growth and development. Journal of Sustainable Tourism 15 (5): 520-40.

Reuters. 2014. Court rejects BP appeal over Gulf spill payouts; says company must honor settlement agreement. http:// www.huffingtonpost.com/2014/03/04/bp-appeal-gulfspill_n_4893270.html?\&;ncid=tweetlnkushpmg00000067 (accessed March 21, 2014).

Roberts, S., and J. Tribe. 2008. Sustainability indicators for small tourism enterprises-An exploratory perspective. Journal of Sustainable Tourism 16 (5): 575-94.

Robinson, L., and J. K. Jarvie. 2008. Post-disaster community tourism recovery: The tsunami and Arugam Bay, Sri Lanka. Disasters 32 (4): 631-45.

Safford, T. G., J. D. Ulrich, and L. C. Hamilton. 2012. Public perceptions of the response to the Deepwater Horizon oil spill: Personal experiences, information sources, and social context. Journal of Environmental Management 113:31-9.

Scholtens, B. 2008. A note on the interaction between corporate social responsibility and financial performance. Ecological Economics 68:46-55.

Sen, S., and C. B. Bhattacharya. 2001. Does doing good always lead to doing better? Consumer reactions to corporate social responsibility. Journal of Marketing Research 38 (2): 225-43.

Sigala, M. 2014. Customer involvement in sustainable supply chain management. A research framework and implications in tourism. Cornell Hospitality Quarterly 55 (1): 76-88.

Singh, T., M. H. Slotkin, and A. R. Vamosi. 2007. Attitude towards ecotourism and environmental advocacy: Profiling the dimensions of sustainability. Journal of Vacation Marketing 13 (2): 119-34.

Sirakaya-Turk, E., S. Baloglu, and H. U. Mercado. 2014. The efficacy of sustainability values in predicting travelers' choices for sustainable hospitality businesses. Cornell Hospitality Quarterly 55 (1): 115-26.

Smith Travel Research. 2012. STR Northwest Trend Report 20062012. Henderson, TN: Smith Travel Research.

Susskind, A. M. 2014. Guests' reactions to in-room sustainability initiatives: A look at product performance and guest satisfaction. Cornell Hospitality Quarterly 55 (3): 228-38.

Tsai, C. W., and C. P. Tsai. 2008. Impacts of consumer environmental ethics on consumer behaviors in green hotels. Journal of Hospitality \& Leisure Marketing 17 (3-4): 284-313.

Van Winkle, C. M., and K. J. MacKay. 2008. Self-serving bias in visitors' perceptions of the impacts of tourism. Journal of Leisure Research 40 (1): 69-89.

Visit Florida. 2011. 2011 Annual report. Tallahassee: Visit Florida.

Visit Florida. 2013. Research-Official media room. http://www. visitflorida.com/en-us/media/research.html (accessed April $28,2015)$.

\section{Author Biographies}

Alex M. Susskind, Ph.D., joined the faculty at Cornell's School of Hotel Administration in the Department of Food and Beverage Management in the Fall Semester of 1998. Through his research program he is currently examining: (a) the influence of customer-service 
provider interaction as it relates to organizational performance from the perspective of guests, employees, and managers; and (b) the influence of communication relationships upon individuals' work-related attitudes and perceptions surrounding organizational events and processes such as sustainability, teamwork, and downsizing.

Mark A. Bonn, Ph.D., is the Robert H. Dedman Professor in Services Management, Dedman School of Hospitality, College of Business, Florida State University.

Benjamin C. Lawrence, Ph.D., is an assistant professor of food and beverage management at the Cornell School of Hotel Administration.
Lawrence earned a Ph.D. in management (marketing) from the Questrom School of Business at Boston University, an MBA from the Mays Business School at Texas A\&M University, and a bachelor's degree from the Cornell School of Hotel Administration. His primary research interest involves channels of distribution with a focus on franchising.

H. Leslie Furr, Ph.D. Dr. Furr worked in the Hospitality Industry Operations with Steak and Ale Corporation, the Marriott Corporation (Springfield, Mass), The Hyatt Regency, (Capital Hyatt, Washington, DC. After obtaining a Ph.D. from Texas A\&M, Leslie initiated two Hospitality programs (Cal State Chico and Georgia Southern University). 